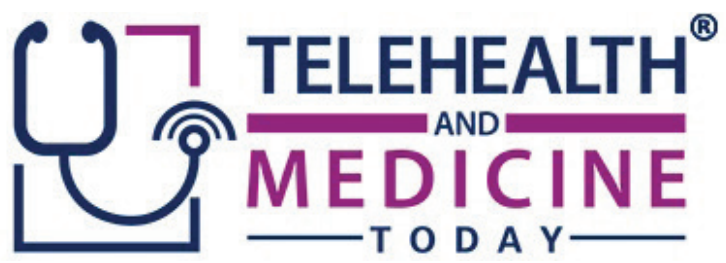

\title{
Innovative Telemedicine Approaches in Different Countries: Opportunity for Adoption, Leveraging, and Scaling-Up
} Amar Gupta, ${ }^{1}$ Mariam E. Dogar, ${ }^{1}$ Emily Sijin Zhai, ${ }^{2}$ Pooja Singla, ${ }^{3}$ Tooba Shahid, ${ }^{1}$ Hilal Nuriye Yildirim, ${ }^{2}$ Sabrina Romero, ${ }^{1}$ Shaurya Singh $^{4}$

Affiliation: ${ }^{1}$ Massachusetts Institute of Technology, Cambridge, MA, USA; ${ }^{2}$ Wellesley College, Wellesley, MA, USA; ${ }^{3}$ SOAR Management Consulting Group, Brookline, MA, ${ }^{4}$ Mallya Aditi International School, Bengaluru, Karnataka, India

Corresponding Author: Amar Gupta, Massachusetts Institute of Technology, Cambridge, MA, USA. agupta@mit.edu.

Keywords: Adoption, China, Cost-saving, Cuba, Digital health, Europe, India, Latin America, Leveraging, Mongolia, Pakistan, Scaling-Up, Singapore, Telemedicine

Section: Production, Deployment

In the age of digitization, a growing percentage of services are becoming available online, and this trend is affecting healthcare too. As evolving technology creates more avenues for physicians to deliver affordable and instant care to their patients, there has been a sharp increase in the number of telemedicine implementations across the world. ${ }^{1}$ As in other disciplines, guidelines and regulations on telemedicine lag behind the use of the technology and are still being crafted and modified. For example, the new nationwide policy on telemedicine of the Department of Veterans Affairs (VA) of the US Government became effective in mid-2018 and incorporates the opinion and recommendations made 7 years earlier. In recent years, the VA spent over $\$ 1$ billion a year on transportation of veterans to and from hospitals; now with telemedicine, this amount can be used increasingly for other purposes. This cost-saving experience at the national scale should alert industry actors, national governments, and consumers of the growing urgency to address the policy and regulatory aspects of telemedicine to provide healthcare services with greater speed, quality, and safety to rapidly increasing percentages of citizens of their respective countries.

I n 2018, the World Health Organization (WHO) published its first guidelines on digital health. WHO defines telemedicine as "delivery of healthcare services, where distance is a critical factor, by all healthcare professionals using information and communication technologies, for the exchange of valid information for diagnosis, treatment and prevention of disease and injuries, research and 
evaluation, and for the continuing education of healthcare providers, all in the interests of advancing the health of individuals and their communities." ${ }^{2}$ Digital health has become a crucial step on the path to attaining universal health coverage and sustainable development goals of the United Nations. This is due to the scarcity of healthcare practitioners worldwide and the ability of digital health to offer a pragmatic solution to address the scarcity.

Countries, regardless of development level, can benefit through various implementations of telemedicine. Digital health is an ever-evolving concept where the government of specific countries and researchers are still exploring how the implementation of telemedicine projects can benefit healthcare systems. This article focuses on the regulation and innovation environments relating to telemedicine in several countries, at various levels of development.

\section{INDIA}

Among India's national population of more than 1.35 billion people, $72.2 \%$ live in rural areas, 3,4 while more than $75 \%$ of doctors are based in cities. ${ }^{5}$ The Indian Telemedicine Act of 2003 defined telemedicine as the "practice of medicine delivered across distances via telecommunications, including audio, visual and data communications, and interactive video technology, performed by licensed or otherwise legally authorized individuals." In 2015,

"National Telemedicine Network" was launched to provide telemedicine services to remote areas from surrounding district hospitals. For example, in Tehri, Uttarakhand, in rural North India, establishment of telemedicine centers and a telemedicine system called "Hello Doctor-555" supports over 60,000 people living in rural settlements spread across $4,080 \mathrm{~km}^{2}{ }^{5}$ With 36 official languages and varying literacy levels, as well as diversity in social, economic, technological, and telecommunication development, the process of implementing telemedicine on a countrywide basis is formidable. The ability to leverage both government and community support to overcome challenges is exemplified by the two projects described in the following paragraphs.

\section{The High Altitude Center Created by Apollo Telemedicine Networking Foundation with Government Assistance}

The Apollo Telemedicine Networking Foundation (ATNF), a not-for-profit organization set up over 125 telemedicine centers across India (including Andaman and Nicobar Islands, located 1,100 miles from the mainland), Pakistan, Afghanistan, Iraq, Sri Lanka, Bangladesh, Nepal, Kazakhstan, Lagos, Sudan, Yemen, and Middle East. ${ }^{6}$ The ATNF is unique in leveraging relationships with different entities ranging from large corporate hospitals and government hospitals to small clinics and information centers in hard-to-reach areas. ${ }^{7}$ One such area is the Himalayas where ATNF - with assistance from the government-has created a telemedicine center 13,000 feet above sea level, perhaps the highest telemedicine center in the world. A telemedicine station at the community health center in the small village of Kaza and another at the regional hospital in the mountain town of Keylong use dedicated satellite connections of 512 kbps and VSee low-bandwidth videoconferencing software to connect with Apollo specialists in hospitals across India.

\section{Uttarakhand Telemedicine}

A major goal in India is the desire by relevant agencies to institutionalize telemedicine services for those living in remote areas. Employers are making the same efforts for their employees posted at such places. One example of this phenomenon is the pioneering effort in the hilly state of Uttarakhand where the cost of 
telemedicine consultation was less than 25 cents, probably among the lowest in the world. ${ }^{8}$

In Uttarakhand, as in the rest of the world, advances in Information, Communication and Technology have made telemedicine a viable approach in rural areas. Indian Space and Research Organization (ISRO), along with Himalayan Institute Hospital Trust, and the district government provide primary healthcare through teleconsultation to remote and hilly tribal areas using village resource centers. These centers were established by ISRO throughout the country in 2010 and now managed by non-government organizations. In addition, Uttarakhand provided satellite connectivity and equipment for communication, tele-education, and telemedicine. ${ }^{8}$

The Government of Tehri Garhwal, a hilly district within Uttarakhand, looked to the use of telemedicine, and with financial assistance of THDC India Limited (formerly Tehri Hydro Development Corporation Limited), contributing INR 61.74 lakhs ( 87,000 USD; 78,000 EUR) on the project, along with ISRO's infrastructure already in place, was able to establish the telemedicine centers.

These centers are run by qualified pharmacists or nurses acting as an interface between the specialist doctor at the control room in the District Hospital and the patient at the village health center. All centers are equipped with a medical kit (briefcase) with pulse oximeter, ECG machine, Wi-Fi ECG recorder, X-ray view box, glucometer, and other essential tools, a comprehensive pathological kit along with an android tablet and a list of essential medicines and portable hot spot to facilitate diagnosis, data transfer and communication with the district hospital. ${ }^{9,10}$

The average telemedicine consultation cost where teleconsultations are provided at these village resource centers is less than INR $15(<1$ USD or EUR) per patient. Approximately $48.7 \%$ of the queries were processed in less than 10 minutes of satellite time, and the physical presence of a doctor was necessary only $30 \%(33 / 115)$ of the time. While approximately $67 \%$ of beneficiaries thought their privacy was not maintained as per their expectations, a request to extend the timing of the session was made by $85 \%$ of clients. Challenges included prolonged nonconnectivity due to communication failure, lack of technical staff, lack of patient's privacy during sessions, and lack of self-sustainable income. Yet, patients benefited because they did not have to travel long distances for medical advice, and easy follow-ups were facilitated. ${ }^{9,10}$

\section{Kumbh Mela Project}

Kumbh is an organized periodic religious gathering of a large number of people from around the world. In 2015, Nashik city hosted over 30 million people, and the event ended without a single fatality ${ }^{11}$ — a testimony to the power of combining the knowledge of the city with the power of social innovation. The "Kumbhathon" team joined hands with Tata Consultancy Services (TCS) to mentor and encourage innovation through a series of tech camps preceding the event.

TCS set up the Digital Impact Square (DISQ), an open innovation center, to create social impact through the use of inclusive design and digital technologies, including telemedicine. Through DISQ, telehealth services were again made operational in a subsequent Kumbh Mela held in 2016 at Ujjain. ${ }^{12}$ More recently in 2019, the Mela administration managed the temporary district during the 55-day fair. The Mela area was divided into 20 sectors, and the government created a temporary hi-tech hospital equipped with ICUs and a capacity of 100 beds.

The outpatient department had a capacity of 
10,000 patients per day, and ambulances with life support system were kept on standby $24 / 7$, successfully leveraging technology to meet the health needs of the community.

\section{CHINA}

China has three major telemedicine networks: Golden Health Network, International MedioNet of China, and the People's Liberation Army. ${ }^{13}$ As economic development across China is disproportionate, smaller hospitals and clinics located in rural areas benefit from connecting with large hospitals to provide teleconsultation, telediagnosis, telemonitoring, and other services. Traditional face-to-face models are inadequate to meet the increasing demand for services due to overpopulation and limited resources. ${ }^{14}$ Telemedicine will become more significant in China as it addresses the disparity between resource-rich and resource-poor areas by promoting medical policies and remote rescue in cases of emergencies. ${ }^{15}$

\section{Xiamen Demonstration Project}

The Xiamen government invested 26.5 million RMB (3.9 million USD; 3.4 million EUR) to provide a medical service platform catering to hospitals, communities, and government agencies, as well as integrate information systems at different levels in hospitals and community clinics to create a centralized data center that facilitates retrieval of citizens' health archives. Of the 3 million residents of Xiamen, the records of more than 1 million inhabitants are now available from birth. The regional collaborative medical platform is used to share information among clinicians and guarantee lifetime health service and management for all Xiamen citizens. It facilitates better relations with third-party companies regarding medical material distribution and delivery, and it enables routine monitoring, disease prevention, and decision support for the national government.
A 2008 analysis showed that 21 million CNY ( $\sim 3.1$ million USD; $\sim 2.7$ million EUR) were saved due to reduction of replicate examinations at medical centers. Medical costs were reduced as consultations became more convenient. ${ }^{16}$ Furthermore, the demonstration project was the first one to successfully associate the electronic health record and the electronic medical record together. The system grew to link hospital institutions with public health and insurance companies across China. After the success of this demonstration project, this system has been piloted on a larger scale in the provinces of Henan, Liaoning, Guangdong, Inner Mongolia, and most recently Gansu. ${ }^{17}$

\section{MONGOLIA}

Mongolia is the most sparsely populated country in the world, yet it is the 18th largest country, with an area of over 1.5 million $\mathrm{km}^{2}(>600,000$ square miles). Specialists are only available in the country's capital, Ulaanbaatar, home to $45 \%$ of the population. About one-third of Mongolia's population live in nomadic culture and have higher maternal mortality rates than other populations. ${ }^{18}$ Telemedicine is the tool to address remoteness and the discrepancy between rural and urban regions in terms of medical services and healthcare resources.

\section{Maternal Care}

The United Nations Population Fund, Ministry of Health of Mongolia, and the government of Luxembourg have worked together to implement telemedicine focusing on maternal care in Mongolia. Currently, 21 provincial hospitals participate in the telemedicine network, which has the potential to reach 40,000 women in rural areas each year. The Swiss Surgical Team provides software, and local doctors are able to consult with experts in real time and to connect with provincial hospitals and the National Center for Maternal and Child Health (NCMCH). ${ }^{19}$ 
For pregnant women living in rural regions who are at risk of complications, telemedicine lifts the financial burden of traveling to Ulaanbaatar to access adequate diagnostic and treatment. Pregnancy complications significantly decreased from $25.7 \%$ of cases in 2007 to $9 \%$ in $2009 .{ }^{20}$ In 1990, 199 women died out of every 100,000 live births in Mongolia. By 2015, that number had dropped to 26 women per every 100,000 live births. ${ }^{21}$

\section{PAKISTAN}

Telemedicine was introduced in 1998 by Elixir Technologies to assess the applicability of telemedicine and telehealth in Pakistan. Subsequent collaborations with ministries of the United States, Japan, and other countries were disconnected from the on-ground realities of the developing countries, and these collaborative programs had little impact. ${ }^{22}$ For this reason, innovative telemedicine start-ups have sprung up around the country led by local medical practitioners who understand the population dynamics and cultural norms of the country.

Among the 182 million residents of Pakistan, $51 \%$ of people lack basic healthcare services primarily because Pakistan spends a mere $0.9 \%$ of its GDP on health. ${ }^{23}$ Another indication of the government's neglect is the fact that public expenditure on health accounts for just one-third of Pakistan's total health expenditure. The $60 \%$ of the population residing in rural areas is disconnected from urban centers due to lack of proper infrastructure and roads.

\section{Sehat Kahani}

While women account for $70 \%$ of the students in medical schools, more than half of female graduates never practice. For many families, a highly qualified doctor daughter-in-law is a status symbol. At the same time, most families insist that women devote their time and attention to their husbands and children after marriage. So, female doctors often forgo their careers after getting married. The limited availability of daycare services at hospitals and at universities, as well as the lack of professional maid services, aggravates the situation. ${ }^{24}$

"Sehat Kahani" (translates to "Story of Health") aims to empower female doctors unable to leave their homes to practice while simultaneously making healthcare accessible in rural areas via telemedicine. Initiated by two visionaries, Sehat Kahani operates 14 clinics with a network of over 500 female doctors who provide direct consultations to over 40,000 patients. Patients pay between $50(<\$ 0.48$ USD, EUR) and 500 ( $<\$ 5$ USD, EUR) Pakistani rupees per visit, which is relatively affordable. This revenue is supplemented by corporate preventive healthcare campaigns as well as from grants and competitions. ${ }^{25}$ Sehat Kahani is addressing several cultural and technological challenges, including making patients comfortable with female doctors, general dislike of females talking in rural communities, encouraging uneducated people to become comfortable with videoconferencing, and applying digital health techniques in a country with internet penetration of only $18 \% .^{24}$

\section{CUBA}

During the 1970s, Cuba established the Center of Cybernetics Applied to Medicine (CECAM) to use telephone and radio communications to improve patient diagnosis. Subsequently in 1998, the Ministry of Public Health Care started working on a national telediagnosis system that incorporates all primary healthcare information centers located in 498 polyclinics, as well as all computer rooms and 76 laboratories that support medical student education. ${ }^{26}$ The national telediagnosis system includes "Universidad Virtual de Salud" (Virtual University of Health Care) and 
"Biblioteca Virtual de Salud" (Virtual Library of Health Care). ${ }^{27}$ The First Virtual Congress of Neurosurgery was held in 1999.

The Cuban constitution specifies that all citizen will receive free healthcare. Ten percent of the country's GDP is spent on healthcare annually, making it possible to provide sufficient financing for the incorporation of innovative health technologies at different levels of care while also maintaining and developing human resources for health in sufficient quantity and quality to serve the country's needs. ${ }^{28}$ The management company for Cuba's medical services has established direct contractual relationships with insurers, associations, national and foreign entities, regional and international organizations, and other duly accredited legal entities, as well as with individuals, providing the benefit of personalizing all the programs and services offered. With a network of hospitals of excellence across the country, both general purpose and specialized, new techniques are applied for a rapid and effective diagnosis in more than 150 therapeutic procedures..$^{29}$ Second opinion consultation is provided via telemedicine, through prepayment, in 11 medical specialties: oncology, dermatology, hematology, ophthalmology, neurosurgery, cardiology, radiology, pathology, internal medicine, plastic surgery, and general surgery.

\section{Registry of Acute Coronary Syndrome}

The Registry of Acute Coronary Syndrome (RESCUE in Spanish) is a professional web-based tool, launched in December 2018, to monitor a set of comprehensive performance attention measures of Acute Coronary Syndromes in the Camilo Cienfuegos General Hospital, Sancti Spiritus, Cuba. It facilitates communication among attending doctors and specialists, and it can be accessed from any mobile device or tablet with Internet connection. This idea arose as a solution to the problem of low prescription rates, administration of beta-blockers, and other pharmacological treatments, as well as the lack of data for 1-year follow-up consults. After the implementation of RESCUE, the administration of beta-blockers was almost doubled without increasing the in-hospital heart failures or the patient's length of stay. ${ }^{30}$

\section{Galen Clinics}

Following the Strategy and Plan of Action on eHealth proposed by the Pan American Health Organization, Cuba began to develop electronic medical records and hired a local company, SOFTEL. They designed the Galen Clinics, a program selected for an award by the International Telecommunications Union in eHealth category in 2016. This hospital information system can be installed in large institutes and polyclinics, and covers media management diagnoses, consultations and hospitalizations, and the issuance of results reports. It also guarantees exchange of references and counterreferences between levels of care, as well as generation of the required statistics. The Galen Clinics allow for registry in INFOMED of a unique medical record of each patient based on his or her identity number. Access to this information is restricted. ${ }^{31}$

\section{LATIN AMERICA}

Although telemedicine can help expand health services to remote areas, current laws in several countries and states mandate that patients should not be treated by doctors from another country or state. The issue of legal barriers to interstate practice of telemedicine in the United States has been researched in the past, ${ }^{32}$ and the Department of Veterans Affairs recently adopted a new nationwide policy in the United States that surmounts these barriers at the state level. ${ }^{33}$ While restrictions related to intercountry barriers to telemedicine are being discussed, it is unlikely that such restrictions 
will be surmounted at a global level in the near future.

Two examples of innovative multicountry initiatives are described here.

\section{SickKids}

SickKids Caribbean Initiative was started in 2013 by a research-intensive hospital located in Canada to help improve the survival rate of patients in the Bahamas, Barbados, Jamaica, St. Lucia, St. Vincent and the Grenadines, and Trinidad and Tobago. This initiative facilitates access to healthcare services for children with cancer and blood disorders, maintains local databases for cancer patients, and connects Caribbean doctors with Canadian specialists. Such asynchronous telemedicine avoids insurance issues that may emerge from Canadian doctors dealing directly with the patient. The consultations take place, as needed, from early diagnosis stages to surgery's procedure. During 2017-2018 and in Jamaica alone, 57,790 newborns were screen-tested for sickle-cell disease. ${ }^{34}$

\footnotetext{
Alentha

Alentha provides pro bono services to people in Mexico, Colombia, Peru, Argentina, and other Latin American services in the form of free telemedical consultations with doctors in the United States and Mexico. For primary care basic consultations, Alentha uses the spare time of doctors working at or via Alentha's call center in Mexico. For specialized consultations, Alentha has partnered with Miami Children's Hospital and other prestigious hospitals that are interested in promoting their services to international patients. Such interaction provides the hospital with the benefit of free promotion. After different trials, Alentha determined that the best way to ensure the use of the services was to provide them initially or partially for free, as the main obstacle to the deployment of telemedicine services in Latin America had been
}

psychological rather than technological. For instance, no legislation prevents a foreign doctor from treating patients in Colombia, but the patients tend to trust a local doctor more. According to Guillermo Sierra, a founder of Alentha, this is due to jargon interfering with the doctor-patient communication and the false notion that the Mexican doctors are not as competent as the US doctors because the former receive lower wages.

In partnership with the Colombian insurance company Colsanitas, Alentha developed an app to facilitate communication between doctors and patients via email, text, and video. Patients tend to make frequent use of this service because it is covered by the insurance payment. Moreover, Alentha recently partnered with the Public Broadcasting Service to create a health channel offering to their audience basic information for common medical issues, as well as an opportunity to reach doctors who answer their specific questions through their website. ${ }^{35}$

Alentha ensures compliance with patient privacy and other applicable laws of concerned Latin American countries. The absence of legislation for electronic prescriptions is a limiting factor. Enactment of such laws can overcome misunderstanding between pharmacist and doctor because of handwriting, thereby, reducing costs, and improving overall efficiency.

\section{SINGAPORE}

Singapore faces increasing healthcare demands due to an aging population and a shortage of healthcare professionals. Telemedicine is commonly used due to a country's vast geographic distance between patients and resources - in this case, Singapore is a small city-state. Thus, telemedicine serves to address the ageing population similar to other developed countries. ${ }^{36}$ The National Telemedicine Guidelines 
(NTG) issued by the Ministry of Health (MOH) of Singapore require that healthcare professionals who want to provide telemedicine services to patients in Singapore must be registered and licensed in Singapore. However, NTG does not specify what would happen if healthcare professionals failed to comply with NTG. Accordingly, one representative ${ }^{37}$ stated that telemedicine in Singapore is not covered by the Private Hospitals and Medical Clinics Act (PHMCA), "which governs hospitals, nursing homes, medical and dental clinics, clinical laboratories, and other healthcare institutions." Instead, doctors using telemedicine are expected to "abide by good professional practices and conduct defined under the Singapore Medical Council's Ethical Code and Ethical Guidelines, and [also] take reference from the NTGs." 38

\section{Licensing Experimentation and Adaptation Programme}

The $\mathrm{MOH}$ will be licensing telemedicine as a service under the new Healthcare Services Act, which will replace the PHMCA by 2020. This is being developed with the help of the Licensing Experimentation and Adaptation Programme (LEAP), a "regulatory sandbox" of Singapore's $\mathrm{MOH}$ through which telemedicine companies can pilot programs in a safe and controlled environment under its supervision to help finalize a set of telemedicine laws for the country. The participants are working with the $\mathrm{MOH}$ on clear boundary conditions, data governance measures, and risk mitigation strategies. Specifically, telemedicine services which provide direct doctor-to-patient interfacing and care are the first to go through LEAP. LEAP was launched in 2018 and the first two participants in the program were WhiteCoat and RingMD. Since then, Mydoc, Doctor Anywhere, Speedoc, MaNaDr, SATA Commhealth, Doctor World, Parkway Shenton, Care + , HiDoc, and Rescue have joined. Other small countries such as Estonia and
Monaco can use LEAP as a telemedicine model and guideline on how telemedicine can be implemented effectively.

\section{The European Union and the European Region}

Approximately one-fifth of 513 million people in the European Union is more than 65 years of age, a proportion projected to reach $29.5 \%$ by $2060 .{ }^{39}$ As a consequence of an aging population, noncommunicable diseases such as chronic obstructive pulmonary disease, cardiovascular diseases, and cancer account for up to $80 \%$ of total deaths. ${ }^{40}$

Almost $28 \%$ of the population in the European Union live in rural areas that are often at significant distances from major hospitals and more specialized service centers. ${ }^{41}$ Although each state in the region is characterized by its own set of social and welfare policies, almost all of them have committed to providing their citizens "universal health care."

\section{E-Care}

Telemedicine was recognized as a standard medical act in France in 2009 in the "Hospitals, patients, health territories" law. Guidelines require patients to give written informed consent for the use of telemedicine and personal data of the patient should be secured. However, these guidelines state that telemedicine services other than teleconsultation, telemonitoring, teleexpertise, and teleassistance can only be used in special cases such as emergency and lack of physicians. ${ }^{42}$ At the time of this study, no nonemergency telemedicine services were being reimbursed by insurance in France, and existing projects were funded by General Interest Mission Budgets, French National Authority for Health, or by agreements among different institutions. ${ }^{43}$ As a result of a change in Social Security Financing Bill in 2018, French Health Insurance 
Fund started to reimburse teleconsultations (with specific video requirements). This policy change has begun to reduce the barriers to the development of telemedicine in France. ${ }^{44}$

E-Care was started in 2014 at the University Hospital of Strasbourg as a project aimed to detect risk situations for cardiac decompensation in patients with stage III heart failure. This project is considered as an example of the "Telemedicine 2.0" wave and makes use of newer Information and Communication Technology. ${ }^{45}$ Between February 2014 and April 2015, 175 patients with a mean age of 72 years and a mean Charlson Comorbidity Index of 4.1 (which predicts 10-year mortality for a patent with comorbid conditions) took part in the E-care project that led to 700 alerts among 68 patients. Follow-up examinations revealed that patients who did not receive any alerts had "no clinically significant events that might eventually have led to hospitalization." 46 So, the platform was successful in detecting indicators of potential worsening of health.

Most European countries are characterized by a strong welfare state orientation. In Norway, the right to quality healthcare is considered fundamental and the national healthcare system reimburses travel costs for public transportation, which account for $2.4 \%$ of the expenditure on specialist health services. Norway became the first country to reimburse telemedicine services in 1996. Despite these facts, telemedicine accounts for less than " $0.1 \%$ of the total outpatient activity," possibly because of lack of infrastructure and interoperability between hospitals. ${ }^{47}$

A randomized controlled trial in 2017-2018 involved 389 patients who came to the Regional Medical Center, where a nurse set up a videoconference with a surgeon at the University Hospital of North Norway. The assisting nurse performed the physical tasks in accordance with the surgeon's instructions. Test results like $\mathrm{X}$-rays were digitally available at the time of the consultation. Patients received regular consultations in the control group. In $32 \%$ of such consultations, assistance was required from a nurse. The economic evaluation was conducted based on data on "actual investment, personnel costs, patient travels, and health outcomes."

A societal perspective was adopted for calculating healthcare costs, private costs, and production loss. The study concluded that using teleconsultation in place of having the patient travel to the hospital costs less as long as there were more than 150 consultations per year. If the distance to the specialist hospital was reduced by $50 \mathrm{~km}$, the teleconsultation method was more effective with a minimum of 314 consultations per year. $^{48}$

\section{The Pregnancy and Newborn Diagnostic Assessment in Mineo CARA (Sicily)}

As the main points of entry for individuals seeking asylum within the European Union, Greece and Italy have experienced difficulties in meeting the basic needs of the refugees. Women constitute about $30 \%$ of asylum seekers in Italy, ${ }^{49}$ and it is estimated that about $14 \%$ of these women are pregnant at the time of their application or become pregnant during their stay at reception centers. ${ }^{50}$

In PANDA (The Pregnancy and Newborn Diagnostic Assessment), a pilot study was conducted in Mineo CARA (Sicily) and a mobile health system was used to provide pregnant refugees with access to high-quality antenatal care. Using an app compatible with android smartphones that allows easy data collection from patients through its simple interface, 150 pregnant women from diverse socioethnic backgrounds participated voluntarily in this study. The study was conducted by an antenatal team consisting of two medical doctors, a social worker, a 
community expert, and a cultural mediator. A solar backpack, which contained medical equipment such as urinary strips, a hemoglobinometer, and rapid tests to screen for HIV, syphilis, and malaria, was used as the diagnostic platform. By the end of the study, $10 \%$ of participants were categorized as high risk based on their data and test results, and were referred to the hospital for further treatment. In all, 824 tickets were registered, and all of them were resolved by the system. The system proved to be stable because no tickets were generated during the last 6 months of the project. More than $90 \%$ of the participating women were satisfied with the project. $^{51}$

This pilot study illustrates how telemedicine and small medical teams can address the health needs of multiethnic population in places with a high percentage of refugees and immigrants in a manner where the vast majority of patients from diverse socioethnic backgrounds are satisfied with the quality of the healthcare provided to them and the underlying cultural and linguistic barriers have been surmounted via technology.

\section{CONCLUSIONS}

Several of these projects were implemented due to a lack of digital healthcare structure and regulation within their own country's respective healthcare systems. Today's ever-evolving technology has played a great part in reducing disparities within healthcare, such as prioritizing maternal care and increasing accessibility to those in rural areas. Even within developed countries, there is a lack of quality care and communication between patients, doctors, and hospitals. Telemedicine is an innovative service that has helped in solving these problems within healthcare and has had a profound impact in various countries with specific projects.

Telemedicine continues to evolve, but does pose challenges because of each country's unique laws and regulations in implementing innovative teleservices. There is not only an overall lack of resources to provide for the increased demand for healthcare services, but also an uneven distribution of geographic availability of these services, worldwide. The challenges are not limited to overcoming technological barriers; changing the mindset of the people has been as challenging as getting appropriate technology. Although pilot projects have been launched, progress has been very slow due to capital infrastructure, the lack of commitment and involvement, a resistance to change the traditional mindset, ethical issues, conflicting values, norms, and interests. Recognizing the need of healthcare, the governments in the countries listed have taken steps at various lengths to support telemedicine. The increasing awareness of telemedicine in the society and international collaboration of such innovative projects as discussed/ illustrated in this article and more in the pipeline may help revolutionize healthcare delivery across countries and within developing and developed countries.

Conflict of Interest: During the past 12 months, Dr Gupta has been paid as a consultant by MITRE Corporation for keynote address on telemedicine at a closed door session to senior officials of department federal government agencies in DC area, McDermott Will Emery for keynote address on AI in Healthcare: Role of Medical Boards, co-organized by Federation of State Medical Boards, Business Incubators Accelerators of The Saudi Technology Development and Investment Company (via MIT) for globally livestreamed keynote address on Using Telemedicine and Artificial Intelligence to Provide Better Healthcare for All: Opportunities and Challenges, co-organized by MIT Hacking Machine, and Walmart Health for work on Telemedicine and Telehealth. 
Contributors: Dr Amar Gupta served as overall coordinator and researcher. Each of the coauthor has looked at a different endeavor in various countries around the world.

Funding Statement: Dr Amar Gupta is an employee of MIT and is partly funded from a research contract signed by Philips.

\section{REFERENCES}

1. Lacktman N, Nerwich DN. Teleconsultation Services for the Mobile Workforce. 2019;12.

2. Classification of digital health interventions. Geneva: World Health Organization; 2018 (WHO/RHR/18.06).

3. Rural India is far behind Urban India in every Indicator of Progress. 2015, December 5 [cited 2019 Jul 16]. Available from: https:// factly.in/rural-india-behind-urban-india-inprogress-indicators/

4. India Population 2019 - Current Population of India. 2019 [cited 2019 Jul 16]. Available from: http://www.indiaonlinepages.com/ population/india-current-population.html

5. Rural population | Data. The World Bank; 2018 [cited 2019 Jul 16]. Available from: https://data.worldbank.org/indicator/ SP.RUR.TOTL

6. Bollineni R. Apollo telemedicine networking foundation. Access Health Int. 2011;18.

7. Projects. Apollo Tele Health Services; 2017 [cited 2019 Jul 16]. Available from: http:// www.apollotelehealth.com:9013/Projects.jsp

8. Wangchuk R. Uttarakhand DM's awardwinning initiative connects citizens to $20+$ health schemes. April 2019 [cited 2019 Sept 16]. Available from: https://www. thebetterindia.com/178305/uttarakhand-iasofficer-hello-doctor-health-governance-india/

9. Post G. THDCIL spearheads telemedicine health scheme in Tehri. Feb 2019 [cited 2019 Sept 16]. Available from: http:// garhwalpost.in/thdcil-spearheadstelemedicine-health-scheme-in-tehri/

10. Suresh S. Nath L. Challenges in managing telemedicine centers in remote tribal hilly areas of Uttarakhand. Oct, 2013 [cited 2019 Sept 16]. Available from: https://www. iapsmupuk.org/journal/index.php/IJCH/ article/view/345

11. Empowering Society by Nurturing Changemakers | DISQ Digital Impact Square. n.d. [cited 2019 Jul 16]. Available from: https://www.tcs.com/disq-empoweringsociety-nurturing-changemakers

12. Tele-health services made operational in Kumbh Mela at Ujjain - ISRO. Indian Space Research Organisation; n.d. [cited 2019 Jul 16]. Available from: https://www. isro.gov.in/tele-health-services-madeoperational-kumbh-mela-ujjain

13. Wang $\mathrm{Z}, \mathrm{Gu} \mathrm{H}$. A review of telemedicine in China. J Telemed Telecare. 2009;15(1):23-7. https://doi.org/10.1258/jtt.2008.080508

14. Li H, Zhang T, Chi H, Chen Y, Li Y, Wang J. Mobile health in China: Current status and future development. Asian J Psychiatry. 2014;10:101-4. https://doi.org/10.1016/j. ajp.2014.06.003

15. Cai H, Wang H, Guo T, Bao G. Application of telemedicine in Gansu Province of China. PLoS One. 2016;11(6):e0158026. https:// doi.org/10.1371/journal.pone.0158026

16. Zhao J, Zhang Z, Guo H, Ren L, Chen S. Development and recent Achievements of telemedicine in China. Telemed E-Health. 2010;16(5):634-8. https://doi.org/10.1089/ tmj.2009.0159

17. Gao X, Xu J, Sorwar G, Croll P. Implementation of e-health record systems and e-medical record systems in China. Int Technol Manag Rev. 2013;3(2):127. https:// doi.org/10.2991/itmr.2013.3.2.6

18. Schellhase J. 21st century nomads: Life in the Mongolian Steppe. September 9, 2015 [cited 2019 April 14]. Available from: All That's Interesting website: https:// allthatsinteresting.com/mongolia-nomads

19. Jenkins T, Baatar T, Suldsuren N. In remote Mongolia, telemedicine connects pregnant women to faraway care. 2015 [cited 2019 April 14]. Available from: https://news/ remote-mongolia-telemedicine-connectspregnant-women-faraway-care 
20. Tsedmaa B, Narmandakh S, Shinetugs B, Khishgee $\mathrm{S}$. Telemedicine support of maternal and newborn health to remote provinces of Mongolia. Stud Health Technol Inform. 2012;182:27-35. https://doi. org/10.3233/978-1-61499-152-6-27

21. Tali D. Mongolia's dramatic improvement of maternal care for Nomads. n.d. [cited 2019 April 14]. Available from: Pacific Standard website: https://psmag.com/ social-justice/mongolia-revamped-maternalhealthcare-for-nomads

22. Malik AZ. Telemedicine country reportPakistan. 2007 9th International Conference on E-Health Networking, Application and Services. 2007;90-94. https://doi. org/10.1109/HEALTH.2007.381611

23. News D. Sehat Kahani, a startup aiming to empower female doctors across Pakistan, raises $\$ 500,000$ in seed funding. March 24, 2018 [cited 2019 Jul 24]. Available from: DAWN.COM website: https://www.dawn. com/news/1396670

24. Bhattacharya A. Pressured to give up their careers, Pakistan's "doctor-wives" are using tech to find work again. September 5, 2017 [cited 2019 Jul 16]. Available from: Quartz India website: https://qz.com/india/1064758/ sehat-kahani-pressured-to-give-up-theircareers-pakistans-doctor-wives-are-usingtech-to-find-work-again/

25. Khuraam SS, Aga IZ. Sehat Kahani The story of health. n.d. [cited 2019 Jul 16]. Available from: Sehat Kahani website: https://sehatkahani.com/

26. Presentación de la Universidad Virtual de Salud. n.d. [cited 2019 May 17]. Available from: http://www.uvs.sld.cu/presentacionde-la-universidad-virtual-de-salud

27. González RI, Rodríguez A. La Telemedicina en Cuba: Antecedentes, Estado Actual y Proyectos en Desarrollo, I Congreso Iberoamericano de Telesalud y Telemedicina y VII Reunión Regional de ATALACC, Lima, Perú, 2014.

28. SUCURSALES PROVINCIALES. n.d. [cited 2019 May 17]. Available from: http://www.smcsalud.cu/smc/es/qsomos
29. Beltrán R, María N, Gómez P, et al. Clínica virtual docente: un espacio formativo para la enseñanza de las ciencias médicas. MEDISAN. 2017 [cited 2019 May 17];21(1):123-33. Available from: http://scielo.sld.cu/scielo. php?script $=$ sci_arttext\&pid=S102930192017000100015\&lng=es\&tlng=es.

30. Rodríguez-Ramos MA. Increasing quality of secondary prevention of acute myocardial infarction by using e-Health. High Blood Press Cardiovasc Prev. 2019;26:81-82. https://doi.org/10.1007/s40292-018-0294-8

31. González, Yaditza, and Susana Antón. "Conectar Salud Con Tecnologías... Una Necesidad De Estos Tiempos”. Granma. $\mathrm{Cu}$, March 20, 2018 [cited 2019 Nov 18], Available from: http://www.granma.cu/ cuba/2018-03-20/conectar-salud-contecnologias-una-necesidad-de-estostiempos-20-03-2018-22-03-27.

32. Gupta A, Sao D. The Constitutionality of Current Legal Barriers to Telemedicine in the United States: Analysis and Future Directions of its Relationship to National and International Health Care Reform, Health Matrix, 2010;21:385-442.

33. "VA Expands Telehealth By Allowing Health Care Providers To Treat Patients Across State Lines". Va.Gov, May 2018, Available from: https://www.va.gov/opa/ pressrel/pressrelease.cfm?id=4054.

34. SickKids-Caribbean Initiative. n.d. [cited 2019 May 18]. Available from: https://www. sickkidsfoundation.com/whyweneedyou/ partnerforbettercare/caribbeaninitiative

35. Sierra G. Phone interview. 2019, April 30.

36. Ooi LC, Koh G, Tan L, et al. National telemedicine guidelines of Singapore. 2015 [cited 2015 Jan 30]. Available from: https:// www.moh.gov.sg/docs/librariesprovider5/ licensing-terms-and-conditions/nationaltelemedicine-guidelines-for-singapore.pdf

37. Bhunia P. Singapore's proposed Healthcare Services Bill to regulate telemedicine and make data contribution to the NEHR mandatory. January 28, 2018 [cited 2019 Jul 21]. Available from: OpenGov Asia 
website: https://www.opengovasia.com/ singapores-proposed-healthcare-servicesbill-to-regulate-telemedicine-and-makedata-contribution-to-the-nehr-mandatory/

38. Loh V. Amid debate about telemedicine, 4 more providers join $\mathrm{MOH}$ regulatory initiative. September 11, 2018 [cited 2019 Jul 21]. Available from: TODAYonline website: https://www.todayonline.com/ singapore/amid-debate-about-telemedicine4-more-providers-join-moh-sandbox

39. European Commission, Directorate-General for Research and Innovation. Population ageing in Europe: Facts, implications and policies: Outcomes of EU-funded research. Luxembourg: Publications Office; 2014.

40. Busse R, Blümel M, Scheller-Kreinsen D, Zentner A. (Eds.). Tackling chronic disease in Europe: Strategies, interventions and challenges. Copenhagen: World Health Organization, Regional Office for Europe; 2010.

41. Statistics on rural areas in the EU - Statistics explained. June, 2018 [cited 2019 Jul 17]. Available from: https://ec.europa.eu/eurostat/ statistics-explained/index.php/Statistics on_rural_areas_in_the_EU\#Population_ distribution_by_degree_of_urbanisation

42. Rasmussen, Janne et al. Universal Solutions In Telemedicine Deployment For European HEALTH Care. United4health, 2016, [cited 2019 Nov 18] Available from: http://united4health.eu/wp-content/ uploads/2017/04/D1.8-v1.2United4HealthFinal-Report.pdf.

43. Renaud Bouvet; Pierre Desmarais; Etienne Minvielle Legal and Organizational Barriers to the Development of eHealth in France, 34 Med. L. 2015:361.

44. LOI n ${ }^{\circ}$ 2017-1836 du 30 décembre 2017 de financement de la sécurité sociale pour 2018. , 2017-1836 § (2017).

45. Andrès E, Talha S, Zulfiqar AA, et al. Current research and new perspectives of telemedicine in chronic heart failure: Narrative review and points of interest for the clinician. J Clin Med. 2018;7(12):544. https://doi.org/10.3390/jcm7120544
46. Andrès E, Talha S, Hajjam M, Hajjam J, Ervé S, Hajjam A. Experimentation of 2.0 telemedicine in elderly patients with chronic heart failure: A study prospective in 175 patients. Eur J Int Med. 2018;51:e11-e12. https://doi.org/10.1016/j.ejim.2018.02.022

47. Alami H, Gagnon MP, Wootton R, Fortin JP, Zanaboni P. Exploring factors associated with the uneven utilization of telemedicine in Norway: A mixed methods study. BMC Med Inform Decis Mak. 2017;17(1):180. https://doi.org/10.1186/s12911-017-0576-4

48. Buvi A, Bergmo TS, Bugge E, et al. Cost-effectiveness of telemedicine in remote orthopedic consultations: Randomized controlled trial. J Med Internet Res. 2019:21(2):e11330. https://doi. org/10.2196/11330

49. Il Presidente Della Repubblica. August 18, 2015 [cited 2019 Jul 22]. Available from: Gazzetta Ufficiale website: https://www.gazzettaufficiale.it/eli/ $\mathrm{id} / 2015 / 09 / 15 / 15 \mathrm{G} 00158 / \mathrm{sg}$

50. Trovato A, Reid A, Takarinda KC, et al. Dangerous crossing: Demographic and clinical features of rescued sea migrants seen in 2014 at an outpatient clinic at Augusta Harbor, Italy. Conflict Health. 2016;10:14. https://doi.org/10.1186/s13031-016-0080-y

51. Borsari L, Stancanelli G, Guarenti L, et al. An innovative mobile health system to improve and standardize antenatal care among underserved communities: A feasibility study in an Italian hosting center for asylum seekers. $J$ Immigr Minor Health. 2018;20(5):1128-36. https://doi. org/10.1007/s10903-017-0669-2

Copyright Ownership: This is an open access article distributed in accordance with the Creative Commons Attribution Non Commercial (CC BY-NC 4.0) license, which permits others to distribute, adapt, enhance this work non-commercially, and license their derivative works on different terms, provided the original work is properly cited and the use is non-commercial. See: http:// creativecommons.org/licenses/by-nc/4.0. 